Article

\title{
Experimental researches on the dynamic behavior of the magnetorheological damper
}

\author{
Alexandru Dobre ${ }^{1, *}$ \\ 1 Polytechnic University of Bucharest, Faculty of Transports, Department of Road Vehicles; \\ alexandru.dobre@upb.ro \\ * Correspondence: alexandru.dobre@upb.ro
}

\begin{abstract}
In the context of improving the comfort and dynamics of the vehicle, the suspension system has been continuously developed and improved, especially using magnetorheological (MR) shock absorbers. The development of this technology which is relatively new has not been easy. Thus, the first widespread commercial use of MR fluid in a semi-active suspension system was implemented in passenger cars. The magnetorheological shock absorber can combine the comfort with the dynamic driving, because it allows the damping characteristic to be adapted to the road profile. The main objective of the paper is to analyze the dynamic behavior of the magnetorheological shock absorber in the semi-active suspension. In this sense, the author carried out a set of experimental measurements with a damping test bench, specially built and equipped with modern equipment. The results obtained from the experimental determinations show a significantly improved comfort when using a magnetorheological shock absorber, compared to a classic one, by the fact that the magnetorheological shock absorber allows to modify the damping coefficient according to the road conditions, thus maintaining the permanent contact between the tire and the road due to increased damping force.
\end{abstract}

Keywords: damper; magnetorheological fluids; current intensity; AMESim, semi-active suspension

\section{Introduction}

When the velocity of a vehicle increases, whether we are talking about cars or trains, the vibrations generated by the interaction of the wheel with the road increase significantly and are deeply felt by their body, leading to major problems related to the ride comfort, quality of the travel, stability and the maintenance of the roads. The vehicle suspension has a very important role in controlling its dynamics, being a very important system both for ride comfort while driving and for maintaining/handling the road. The road oscillations are a risk factor for passengers of the vehicles, but also a discomfort at the same time [1-3].

The magnetorheological damper is based on rheological fluids, which can change their viscosity when a magnetic field operates on them. A MR fluid consists of a mixture of oil (usually a silicone oil) and micro-particles sensitive to the magnetic field (for example iron particles). The MR fluid behaves like a normal liquid when magnetic field is not applied. When a magnetic field is applied to the MR fluid, the particles form chains and the fluid becomes very viscous.

The induced force depends directly on the amount of magnetic flux density developed in the effective fluid flow gap of the MR shock absorber. In last years, magnetorheological fluid (MR) technology has received much attention and therefore demonstrated improvement. Its adaptive behavior has led to a rapid growth in such varied engineering applications as basic insolation of civil structures, vehicle suspensions, and several bio-engineering mechanisms through its implementation in various basic MR fluid devices, especially in MR shock absorbers [4,5]. Through different types of signals applied to the suspension, which represents the excitation of the road, the dynamic behavior of the suspension can be highlighted [6]. Many suspension systems/methods can be used to isolate the vibrations transmitted, such as vehicle suspension systems, cabin suspension systems and seating suspension systems [7]. 
The design and analysis of the magnetic circuit is an important stage in the design of the magnetorheological shock absorber. The damping force depends on the intensity of the magnetic field, which is affected by the construction of the magnetic circuit and the associated parameters, as well as the diameter of the piston. Unlike passive suspension, variable magnetorheological shock absorber of semi-active suspension can be effectively controlled in terms of shock absorber stiffness based on required values in a particular situation [8,9]. As stiffness and damping emulations in semiactive actuators are coupled quantities the control is formulated to prioritize the frequency control by the controlled stiffness [10].

In an MR damper the piston contains coils capable of providing a magnetic field in the holes. Under these conditions, the piston can be considered as a magnetorheological valve, and the damping is the result of the friction between the magnetorheological fluid and the orifices Figure 1.

The area between the neighboring poles is a route of natural flow. In the middle region of the pole there is a strangulation of the flow and the saturation in this area must be avoided, because it is a critical area for the performance of the shock absorber [11]

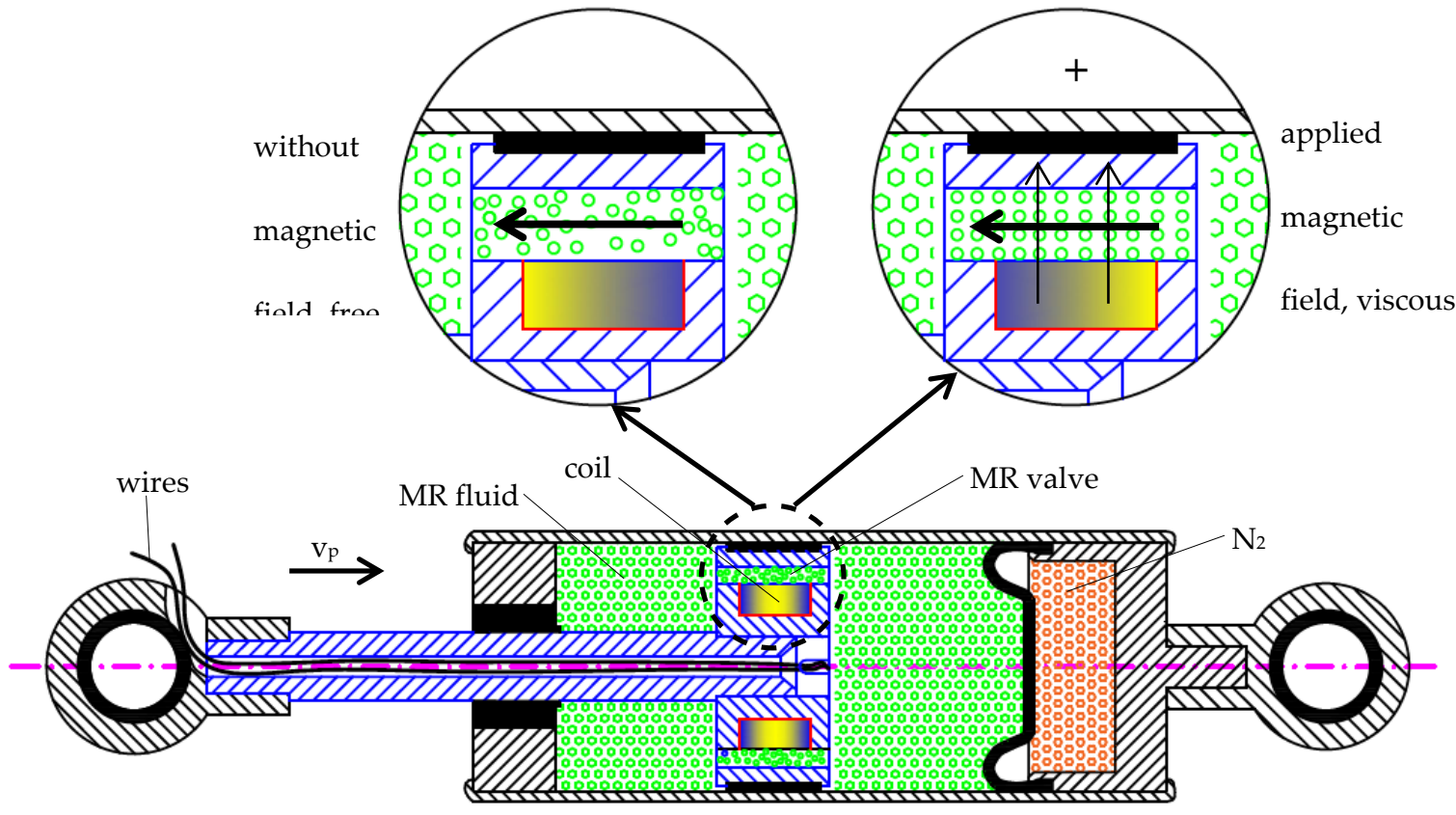

Figure 1. Schematic diagram of a MR shock absorber.

When the coil (located inside the piston) is supplied with voltage by means of an electrical impulse emitted by the electronic control unit, a magnetic field is generated which produces the alignment of the magnetic particles. When the coil is not supplied with electricity, the magnetorheological fluid doesn't magnetize, and the iron particles are randomly dispersed inside the fluid, and the fluid behaves like a conventional hydraulic oil. When the coil is supplied, the magnetic field causes the particles to align in the direction of the magnetic flux. The bond strength between the particles is proportional to the strength of the magnetic field. They are positioned transversely to the direction of oil flow, thus limiting the flow of fluid through the piston grooves. The magnetorheological damper can change the damping characteristic much faster compared to a conventional adaptive damper. With this type of fluid, you can control the stiffness and viscous damping Figure 1.

Depending on the type of damping force variation mechanism, the dampers can be passive, manually adjustable, adaptive [12]. Using only mechanical valves, passive shock absorbers do not require auxiliary power or control. The manually adjustable ones contain electromechanical actuators, which allow a selection of the preset characteristics of the shock absorber valves. Adaptive systems are autonomous and have the capacity to generate force according to road conditions. The available systems are found in several variants, from those with two positions to continuously 
variable systems. Modification of the stiffness of the suspension, associated with the modification of the damping (so that the relative damping remains unchanged) leads to low variations in the comfort of the vehicle and the safety of ensuring the permanent contact of the wheels with the road. When moving the vehicle, the dynamic forces taken over by the shock absorbers are quite high.

There are numerous studies in the literature based on adaptive control methods, which have the role of producing an improvement in the properties of vehicle suspensions [13-16].

Electronically controlled active suspensions can substantially improve driving comfort as well as the road holding of the vehicle.

When the load of the vehicle changes, the suspended mass varies within quite large limits. As the load decreases, there is an increase in relative damping, which is essential for the amplitude of the low frequency oscillations. When the suspended mass decreases, the natural frequency increases, favoring the appearance of the resonance phenomenon at the usual travel speeds. If the damping factor is maintained when the load decreases, the comfort at resonance decreases.

\section{Materials and Methods}

\subsection{Control strategy}

The semi-active control system performance can be generally improved in an active way, without using large energy sources. The necessary external energy needed to generate the desired control forces of an intelligent suspension it is an important problem that needs to be taken in account in the makings of the controller. For obtaining the desired damping force in a controllable area, we can use three main semi-active methods of control that are different: skyhook, ground hook and skyground hook. One of the most popular control logics for the semi-active control systems is the control algorithm Skyhook, because this algorithm is very simple to formulate and easy to implement in practice.

An example for the skyhook controller appliance, that keeps account of the damping control force for the MR damper it is showed in the Figure 2.

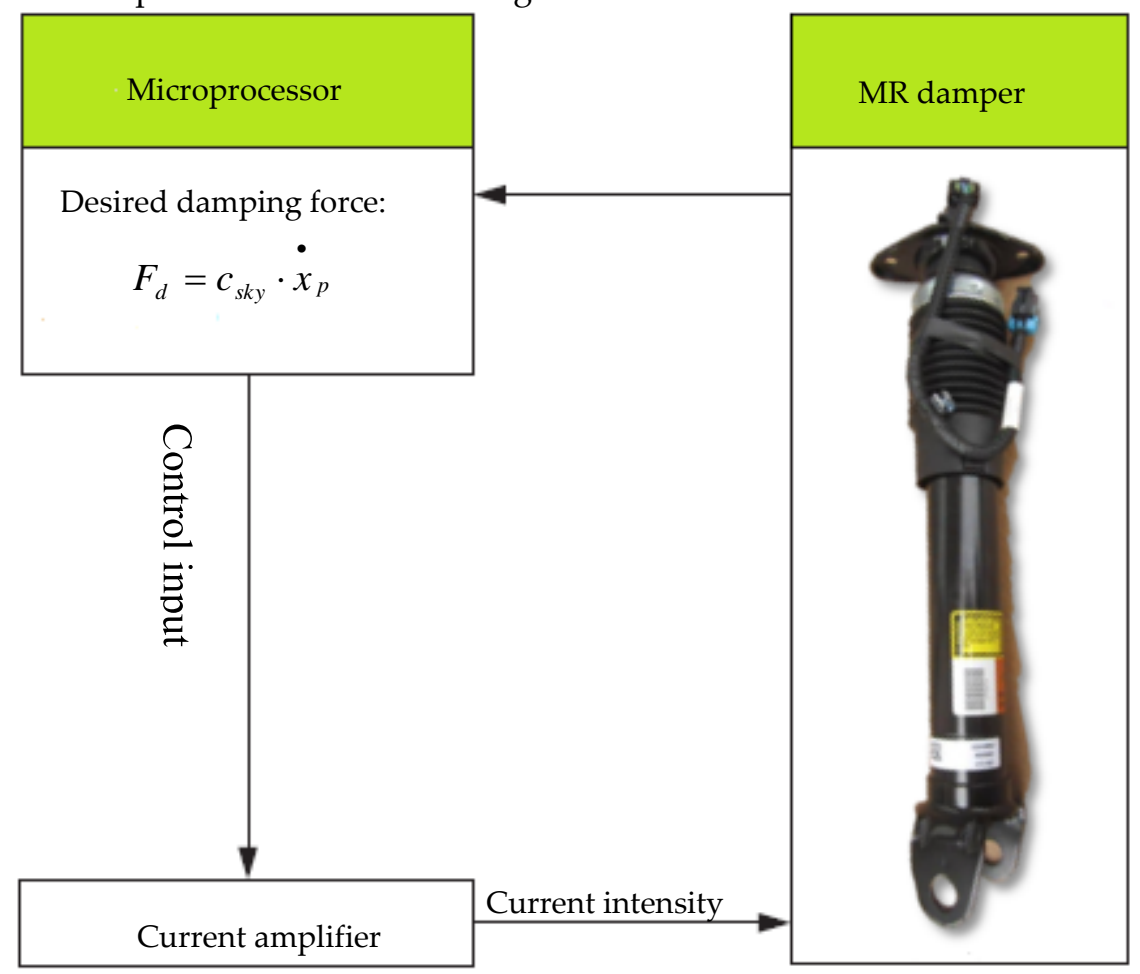

Fig. 2 Skyhook damping force control of an MR damper 
The principle of this approach is to design an active suspension control so that the chassis is "linked" to the sky in order to reduce the vertical oscillations of the chassis and the axle independently of each other [17]. The damping force of the damper can be derived from:

$$
F_{d}=k_{g} \cdot \dot{x}_{p}+c_{e} \cdot \dot{x}_{p}+F_{M R}(H)+F_{f},
$$

where

$\mathrm{kg}=$ the gas chamber stiffness;

$\mathrm{Ce}_{\mathrm{e}}=$ the equivalent viscous damping ratio;

$F_{M R}$ - the controllable damping force;

$\mathrm{F}_{\mathrm{f}}$ - the friction force;

$\dot{x}_{p}-$ the piston velocity;

The controllable damping force depends on the magnetic field $H$. Generally, to implement the MR damper in the suspension system of the car we require a high damping force in the extension movement and a small damping force in the compression movement. If $\dot{x}_{p} \geq 0$ the piston of the damper is in extension stroke and $F_{d}=C \cdot \dot{x}_{p}$ (C = control gain). If $\dot{x}_{p}<0$ the piston of the damper is in compression stroke and $F_{d}=F$ in the absence of the magnetic field [17]. To find a good compromise between comfort and maneuverability one way is to shape a skyhook damper. The skyhook damper adapts to the road conditions and minimizes the pitching and rolling tendencies of the automobile.

\subsection{Magnetorheological dampers test bench}

The test bench, designed and made by the author, consists of the main components: electrohydraulic servomechanism, position transducer, force transducer, velocity transducer, accelerometer, hydropneumatics accumulator, MR shock absorber, servo valve, servo cylinder etc. For the control of the electrohydraulic servomechanism and for the acquisition of the measured data, a PXI type industrial electronic computer is used, provided with a data acquisition board produced by the National Instruments corporation, assisted by the LabVIEW program produced by the same corporation. The excitation of the magnetorheological shock absorber is done with a position signal, like to the real operating situation, a signal which, depending on the type of test performed, can be sinusoidal, triangular or compound. The output quantity is the damping force developed by the magnetorheological damper, corresponding to the different load velocities. A high speed piezo ceramic force transducer (MTS) is used to measure the damping force developed by the shock absorber. The velocity of the stroke piston is measured by an inductive contactless transducer (SCHEWITZ).

The servomechanism subjected to the experimental research was of electrohydraulic type and had the following characteristics: hydraulic motor type: linear, symmetrical, total piston stroke: 200 $\mathrm{mm}$, piston usable area: $7.65 \mathrm{~cm}^{2}$, electrohydraulic amplifier type: BOSCH OBE, MOOG series D76 or equivalent, type of electronic controller: linear PID, position transducer type: inductive, non - contact, or resistive, two - track, rated operating pressure: $21 \mathrm{MPa}$. The principle scheme of the installation used for performing the experimental identification is presented in Figure 3 and Figure 4 and the principle scheme of the tested electrohydraulic servomechanism is presented in Figure 5. The electrohydraulic servomechanism is composed from servo cylinder equipped with the proportional distributor and position transducer. In the case of electromechanical test stands, the frequency is usually changed using either a DC motor or a speed reducer. Electrohydraulic test systems, much more elastic in terms of control signals, allow easy modification of both sizes of interest. The performance tests are necessary to verify if the parameters of the manufactured dampers fall within the prescribed tolerances. Detailed tests have shown that the dampers are very sensitive to changes in valve size (even of the order of $0.01 \mathrm{~mm}$ ) or changes in flows (by changing the clearance or viscosity of the working fluid). The verification of the theoretically deduced characteristics is necessary to validate the analysis method and to ensure a solid basis for the design activity. This involves the individual testing of the elements, subassemblies and the assembled damper, aiming at correlating the aspects deduced theoretically with the experimental results. 


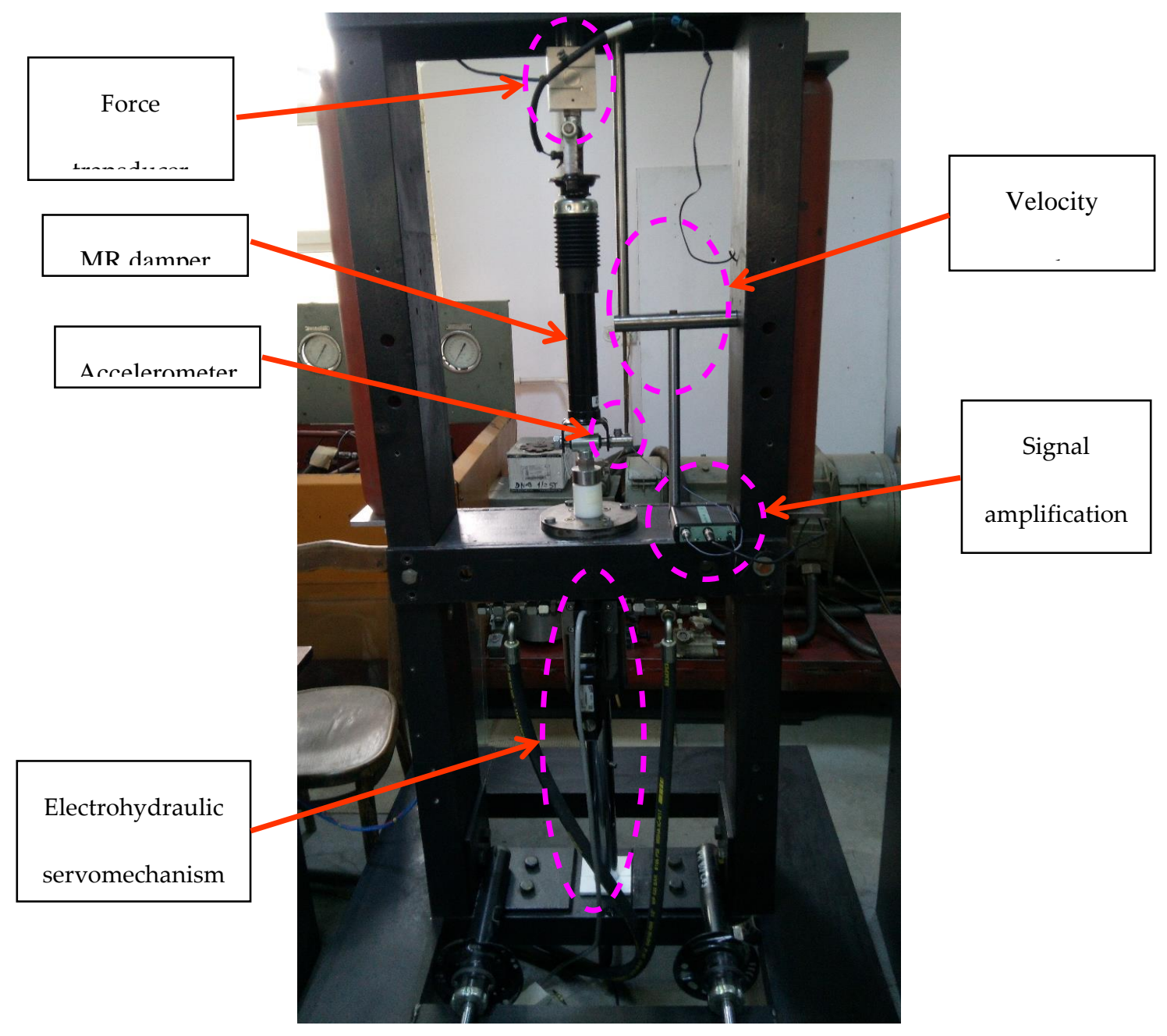

Fig. 3 A part of the installation for testing magnetorheological dampers

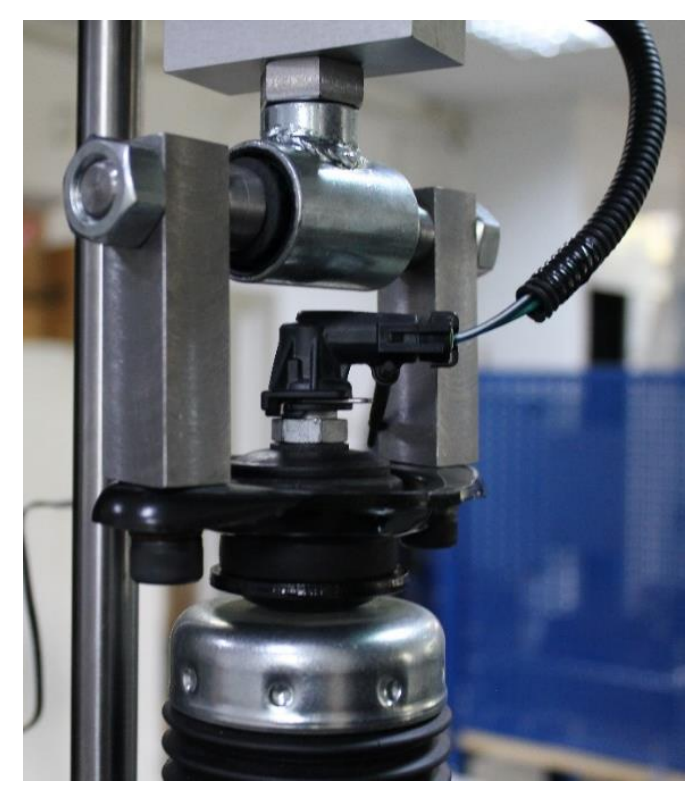

(a)

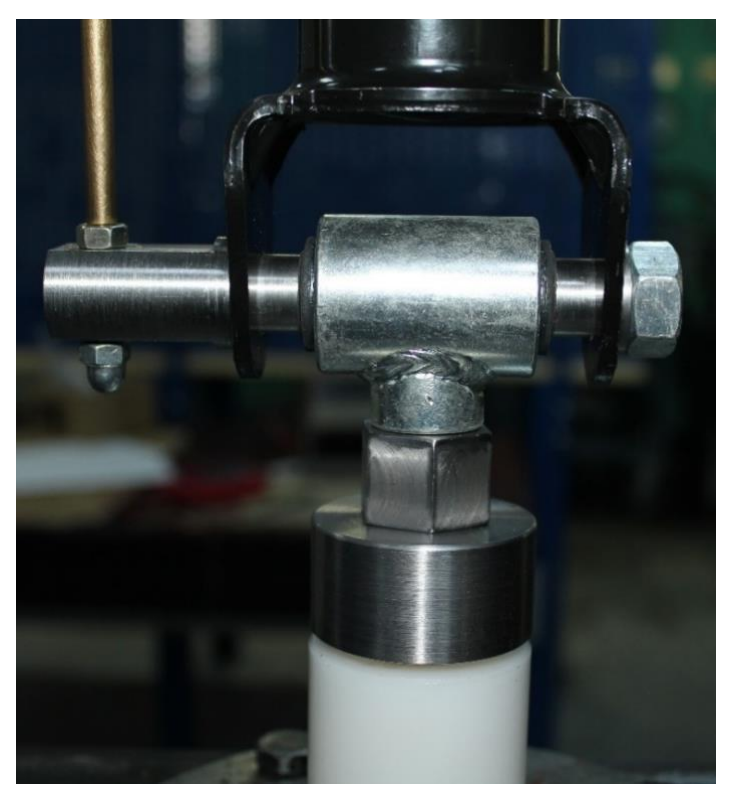

(b)

Figure 4. Details regarding the mounting of the shock absorber in the rigid frame of the stand: (a) Detail regarding the mounting of the shock absorber at the top; (b) Detail regarding the mounting of the shock absorber at the bottom 
As the data values, except temperature, change continuously during a cycle, they cannot be displayed using analog or digital meters. Therefore, this data is usually recorded using data acquisition systems and is then presented, either directly in graphical or tabular form. The derived quantities are approximately constant and can be displayed digitally (even in the case of tests performed with constant velocity and amplitude, their value changes due to the change in temperature).

To determine the regulation characteristic, the reference signal used was a triangular signal with an amplitude of $9 \mathrm{~V}$ and a frequency of $0.02 \mathrm{~Hz}$, which provided the servomechanism with a quasistationary operating mode (piston speed was $3.6 \mathrm{~mm} / \mathrm{s}$ ). The sampling frequency was in this case 10 $\mathrm{Hz}$. The registered characteristic is presented in Figure 6.

Figure 5. Schematic diagram of the tested electrohydraulic servomechanism: 1 - assembled body; 2 - piston; 3 - composite sealing; 4 - anti-friction ring; 5 - anti-friction ring; 6, 7, 10 - "O" rings; 8-compound seal; 9 - lid; 11 - felt ring; 12 - lid; 13 - grower washer; 14 - screw; 15 - position transducer; 16 - nut; 17 - lid; 18 - transducer support; 19 - screw; 20 - grower washer; 21 - limiter; 22 - screw; 23 - grower washer; 24 - support ring; 25 - lid, 26 - gasket; 27 - screw; 28 - servo valve

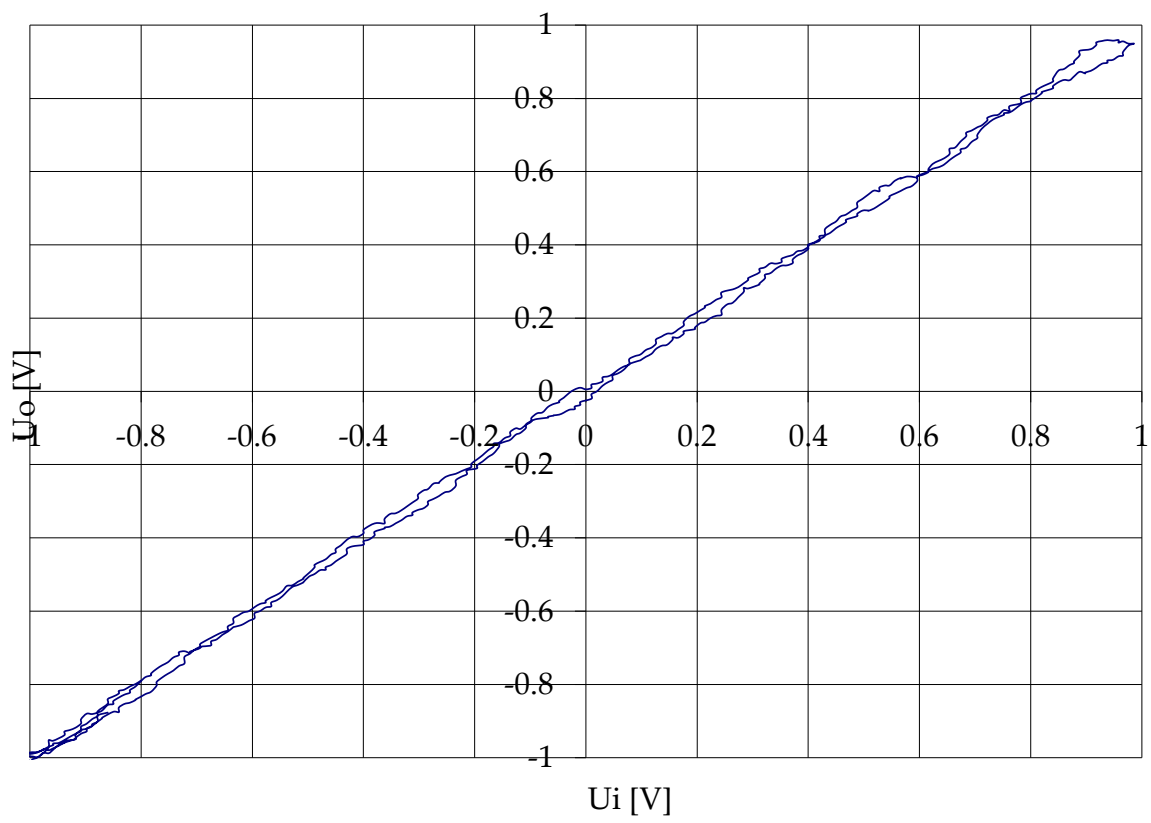

Figure 6. Schematic regulation characteristic of the electrohydraulic servomechanism

The temperature of the oil in the shock absorber and its body varies sufficiently slowly, being the cumulative result of energy dissipation during the test and of the limited cooling possibilities. Temperature certainly influences performance and tends to reduce the damping force for a given 
speed. Also, the force due to the gas pressure and its corresponding rigidity increase with increasing temperature. Under these conditions, temperature monitoring is required. This can be easily done using a thermocouple, together with the appropriate display element.

Figure 7 shows the interface of the LabView work program, with the aid of which the main data acquisition program was developed.

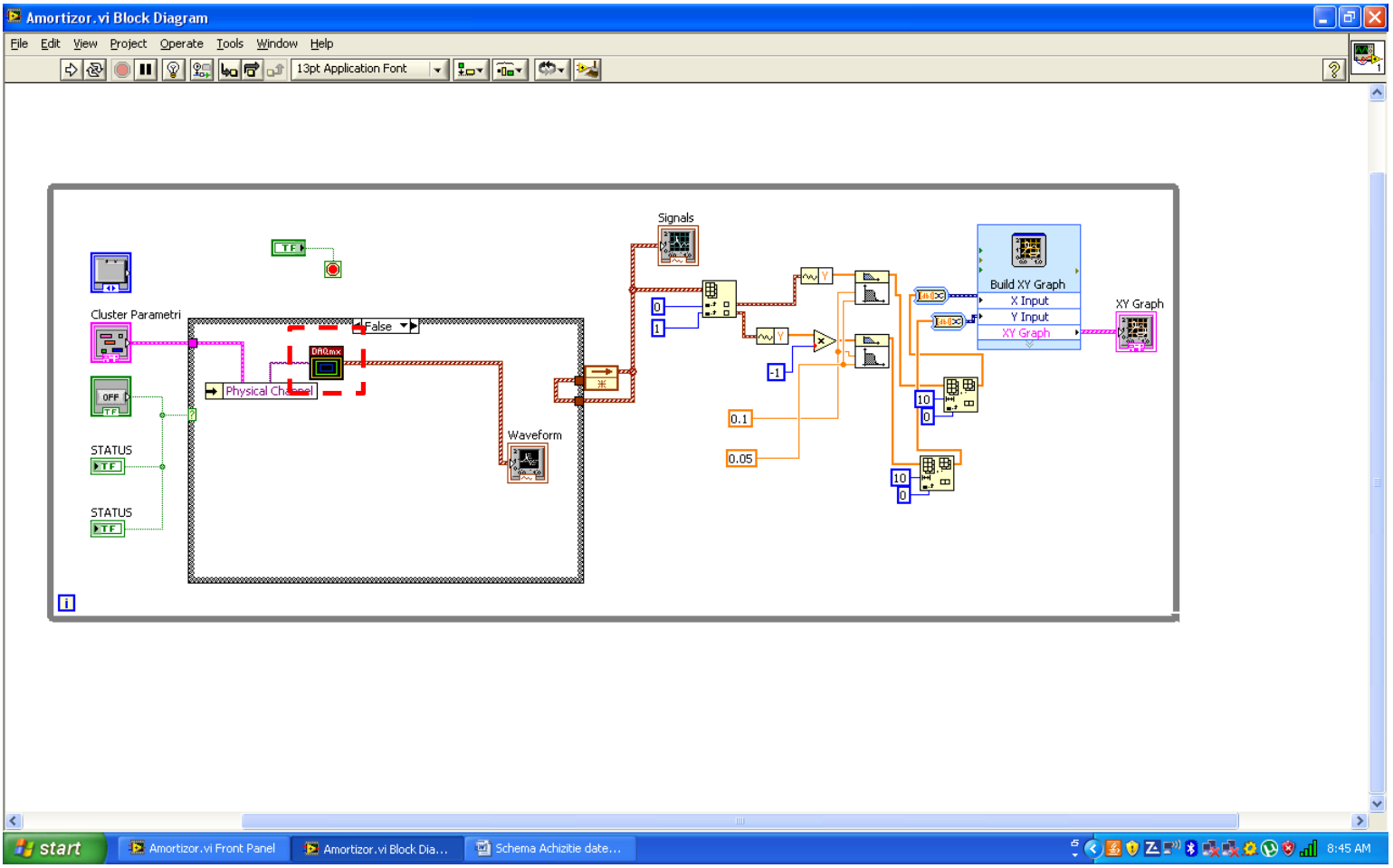

(a)

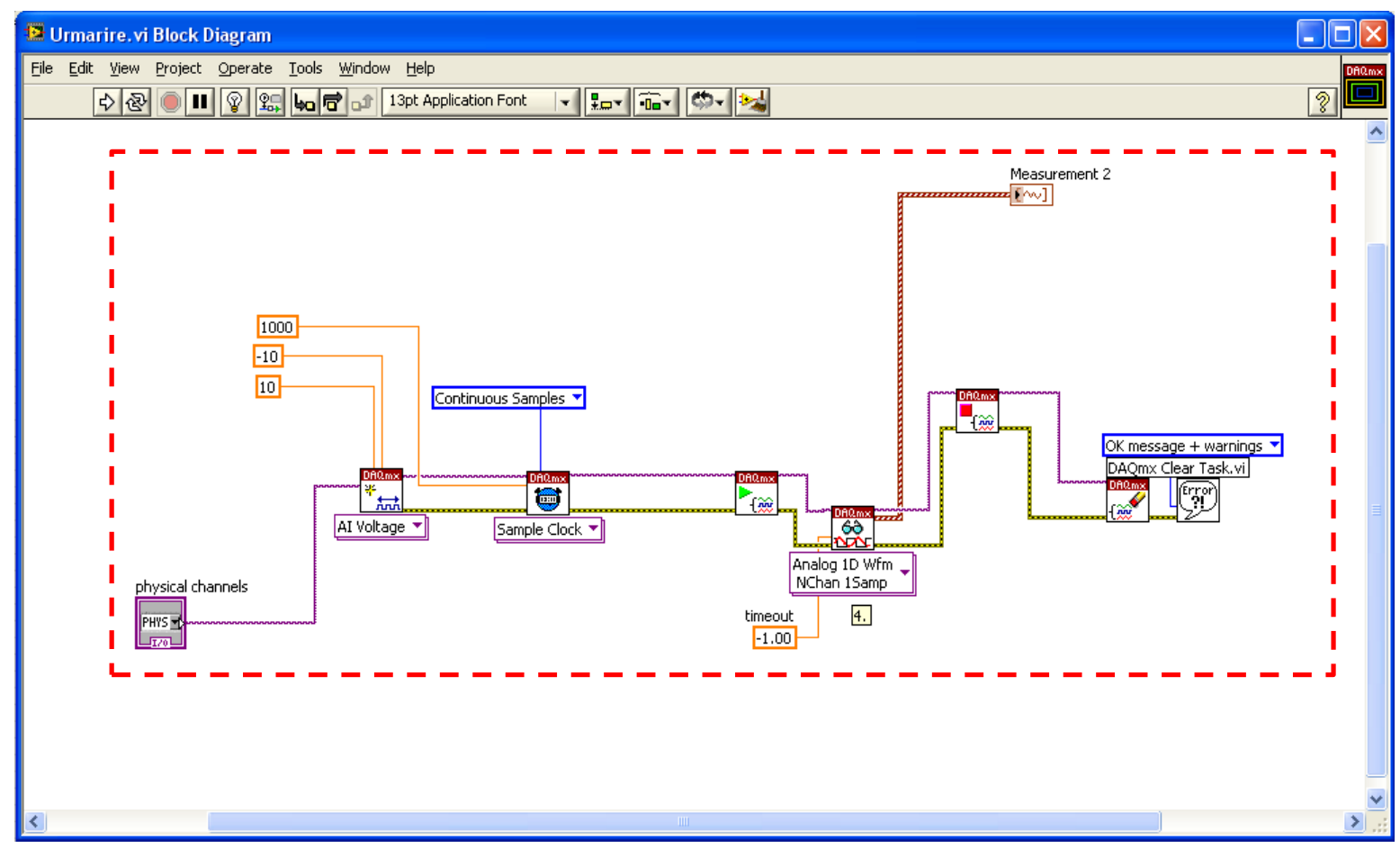

(b)

Figure 7. The data acquisition model in LabView: (a) The main data acquisition program; (b) The data acquisition subprogram 


\section{Results}

In this chapter I will present some the experimental results of the tests of classical and magnetorheological shock absorbers, in order to analyze their dynamic behavior. An example of a typical and practical simulation of a suspension equipped with a classic shock absorber is also presented in this chapter.

In recent years, a new language for modeling and numerical simulation of technical systems has emerged, called AMESim, developed by professors Lebrun and Richards in 1997. The language has been used successfully in both industrial and academic settings. The language allows the assembly of the mathematical models of the studied processes from correct models of technical components stored in the libraries written in the $C$ programming language [18].

The simulation was performed using the AMESim program. The shock absorber was modeled according to the closed loop control law. Using a closed loop control law, we can consider a nonlinear compensation law. This compensation law imposes that we need to measure the pressure in the actuator cylinder (or the force) and the actuator velocity. Indeed, the aim is to adapt the gain of the system to the time constant due to hydraulic volumes of the cylinder and the restriction. The AMESim model of the actuator with the variable gain and the non-linear compensation law is presented in Figure 8 and response damper in Figure 9 and Figure 10.

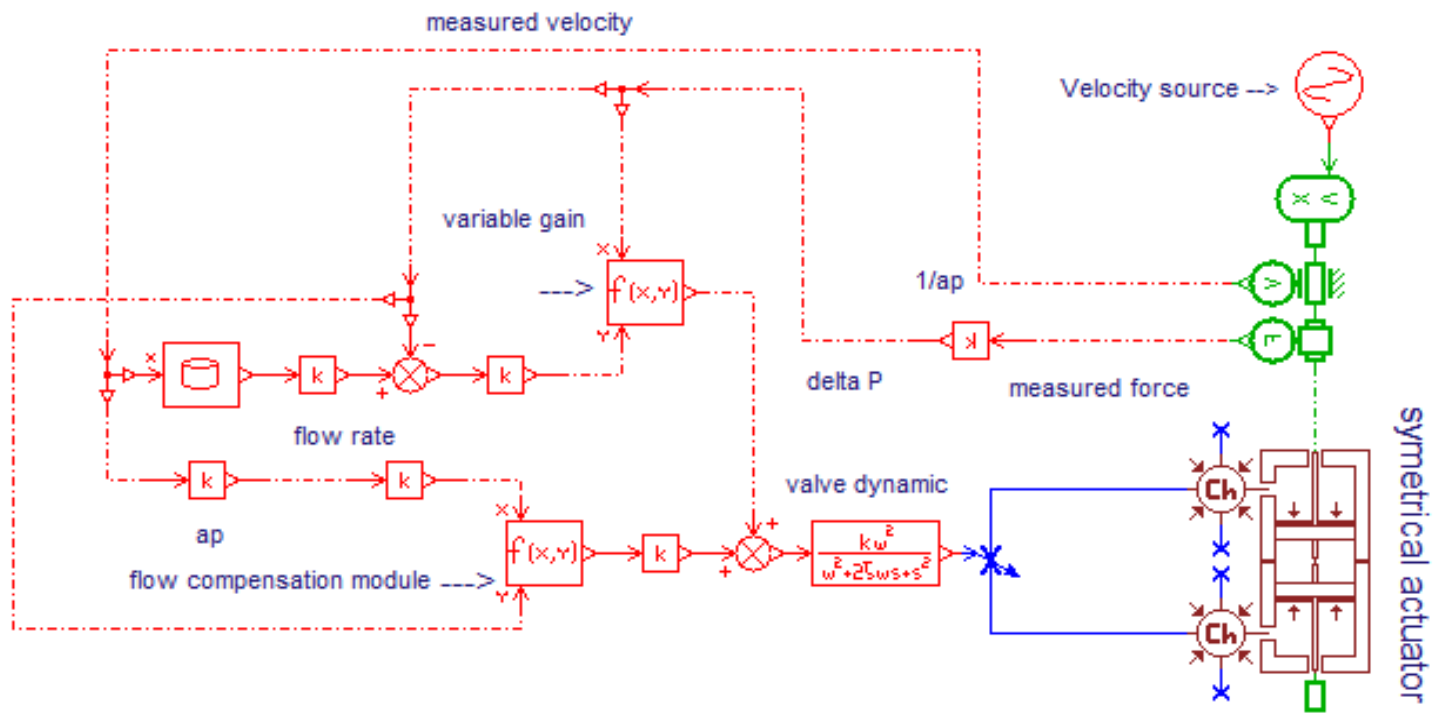

Figure 8. Model of a force control actuator based on a non-linear close loop control law

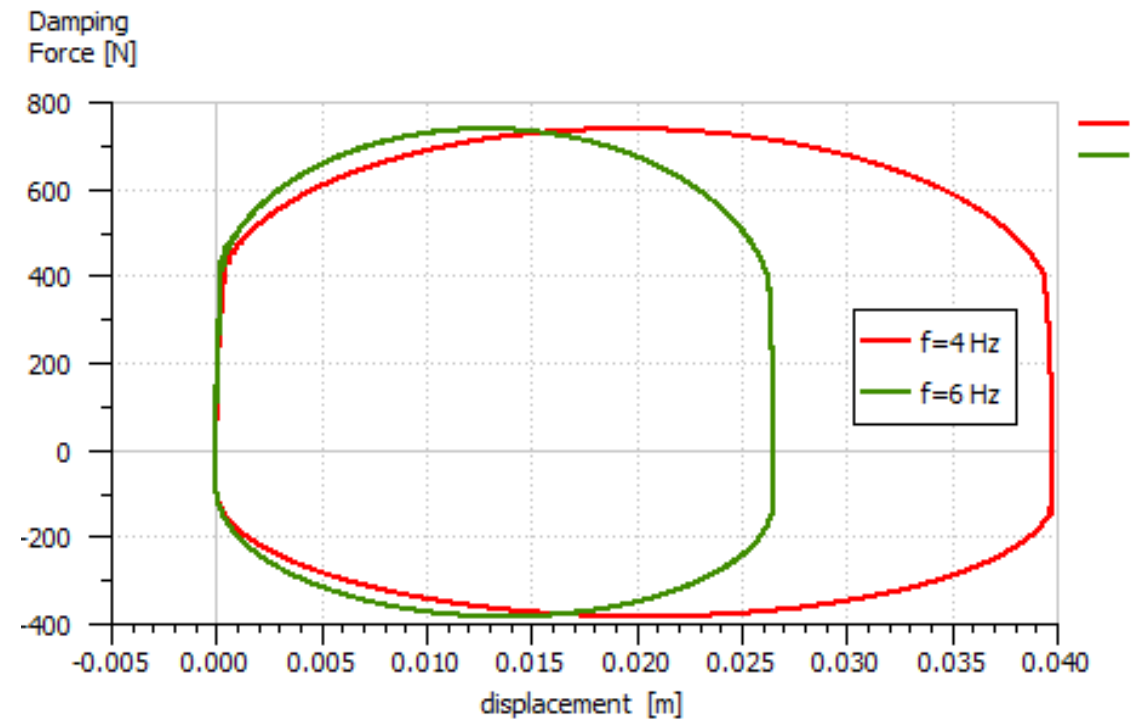

Figure 9. The damping characteristic simulated in force-displacement coordinates for a classic shock absorber 
The theoretical characteristics of this classical device supplied by modeling and simulation are shown in Figure 9 and Figure 10. The road excitation signal (input signal) was approximated with a sinusoidal signal with a frequency of 4 and $6 \mathrm{~Hz}$. At low frequencies (up to about $4 \mathrm{~Hz}$ ) the reference is very well. At high frequencies (starting at about $6 \mathrm{~Hz}$ ) the response may be better, but instead oscillations occur, especially when changing the slope Figure 10.

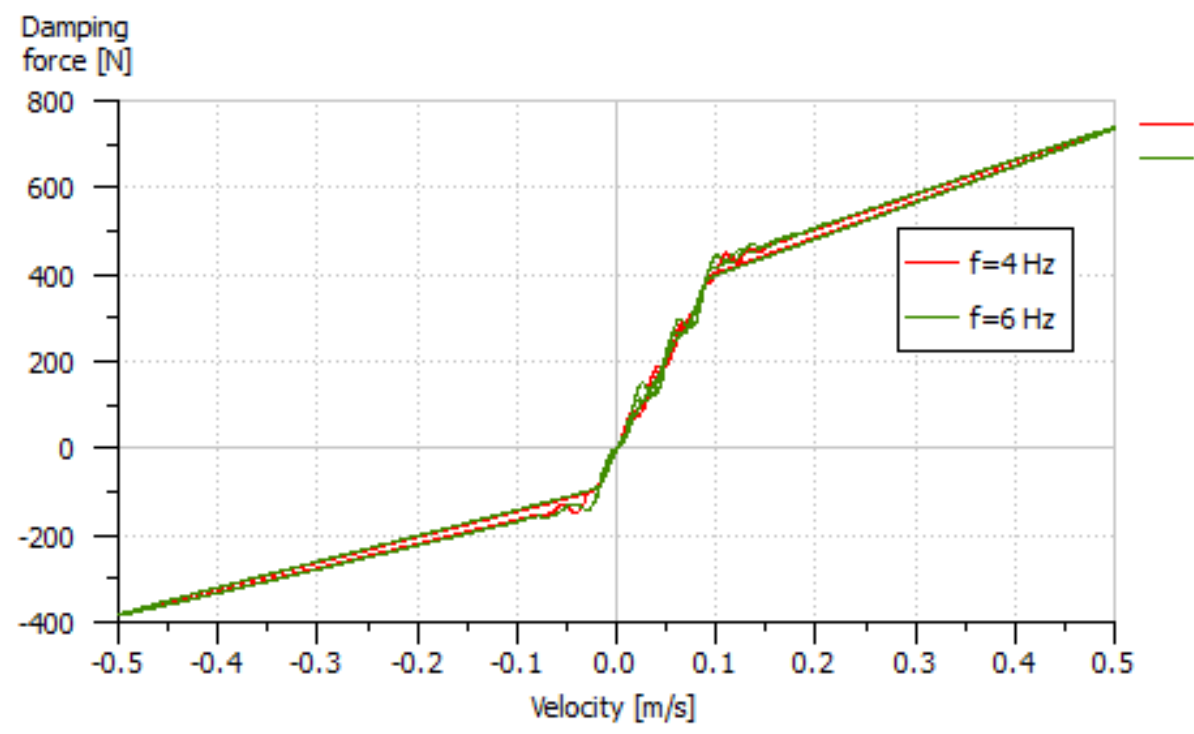

Figure 10. The damping characteristic simulated in force-velocity coordinates for a classic shock absorber

The force / velocity characteristic generated by the closed loop actuator has been improved, compared to the open loop one. The modeling of the vehicle suspension is of great interest for road vehicle engineers, but also for vibration engineers.

The damper simulation model was validated by experimental test. Some results obtained for a classical damper are presented in the Figure 11 and Figure 12. The curves have been obtained by the test bench presented in figure 3, in which the magnetorheological shock absorber was replaced with a classic one. The maximum force sites in the range $(-1000 \mathrm{~N} \ldots+1000 \mathrm{~N})$ for a velocity of the piston sited in the range $(-200 \mathrm{~mm} / \mathrm{s} \ldots+200 \mathrm{~mm} / \mathrm{s})$. The classic shock absorber tested is new and was bought by the author. It is equipping a Chevrolet Corvette car.

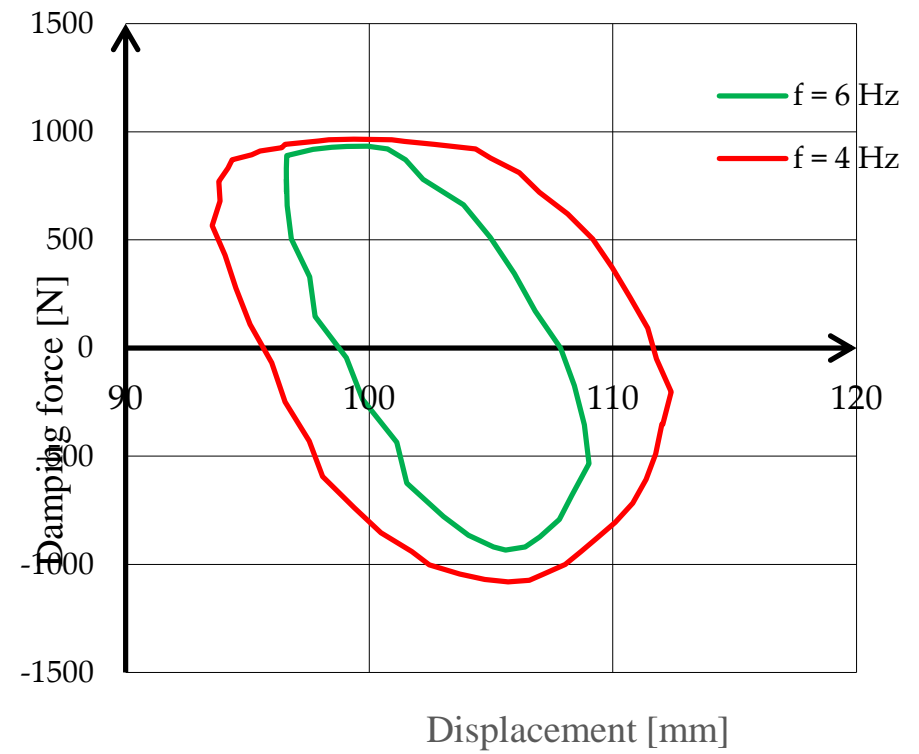

Figure 11. The damping characteristic determined experimentally in force-displacement coordinates for a classic shock absorber 
The input signal is a sinus type, and the frequencies at which the damper was tested are 4 and respectively $6 \mathrm{~Hz}$. The test bench was also used for testing a modern magnetorheological damper. During the shock absorber testing, the two main characteristics were determined, which define the behavior of the shock absorber. The characteristics were determined using the three transducers: speed, force and position.

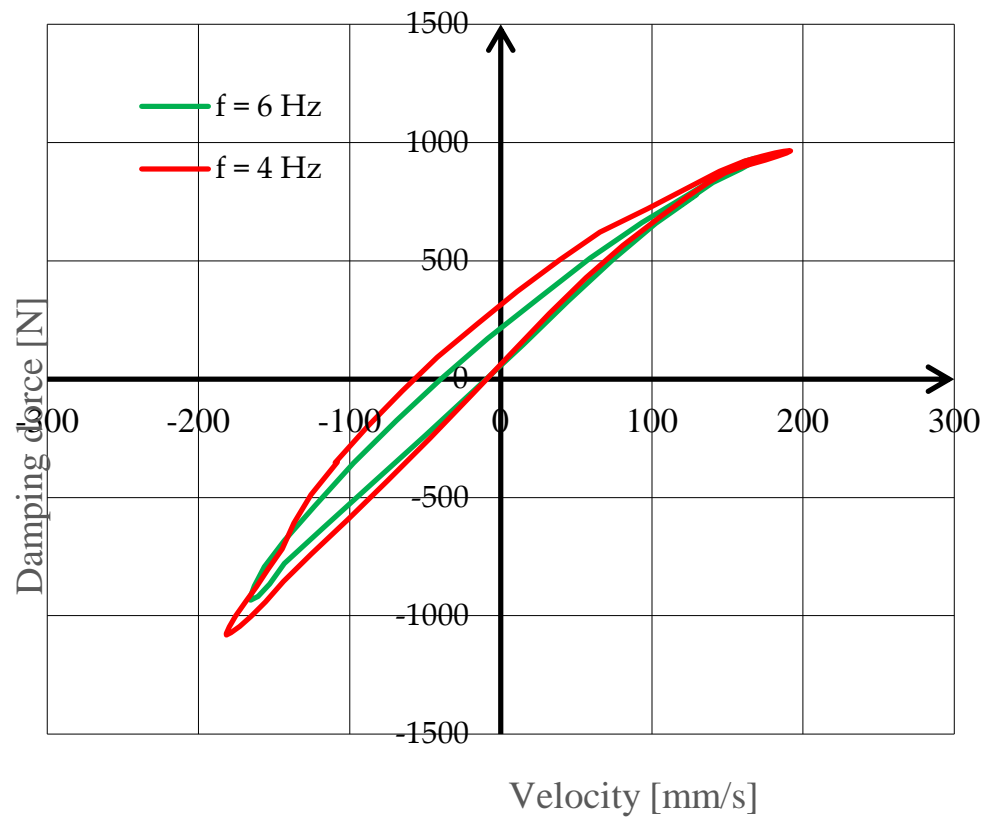

Figure 12. The damping characteristic determined experimentally in force-velocity coordinates for a classic shock absorber

The following is a set of experimental determinations regarding the dynamic behavior of a magnetorheological shock absorber. The shock absorber is new and was purchased directly by the author. The shock absorber equips a Chevrolet Corvette passenger car.

A triangular and a rectangular signal were chosen as excitation signals. The value of the electric current intensity is $0.5 \mathrm{~A}$, and the excitation frequency is $0.3 \mathrm{~Hz}$ Figure 13. The rectangular signal characterizes the operation of the shock absorber in heavy driving conditions, and the triangular one in light driving conditions.

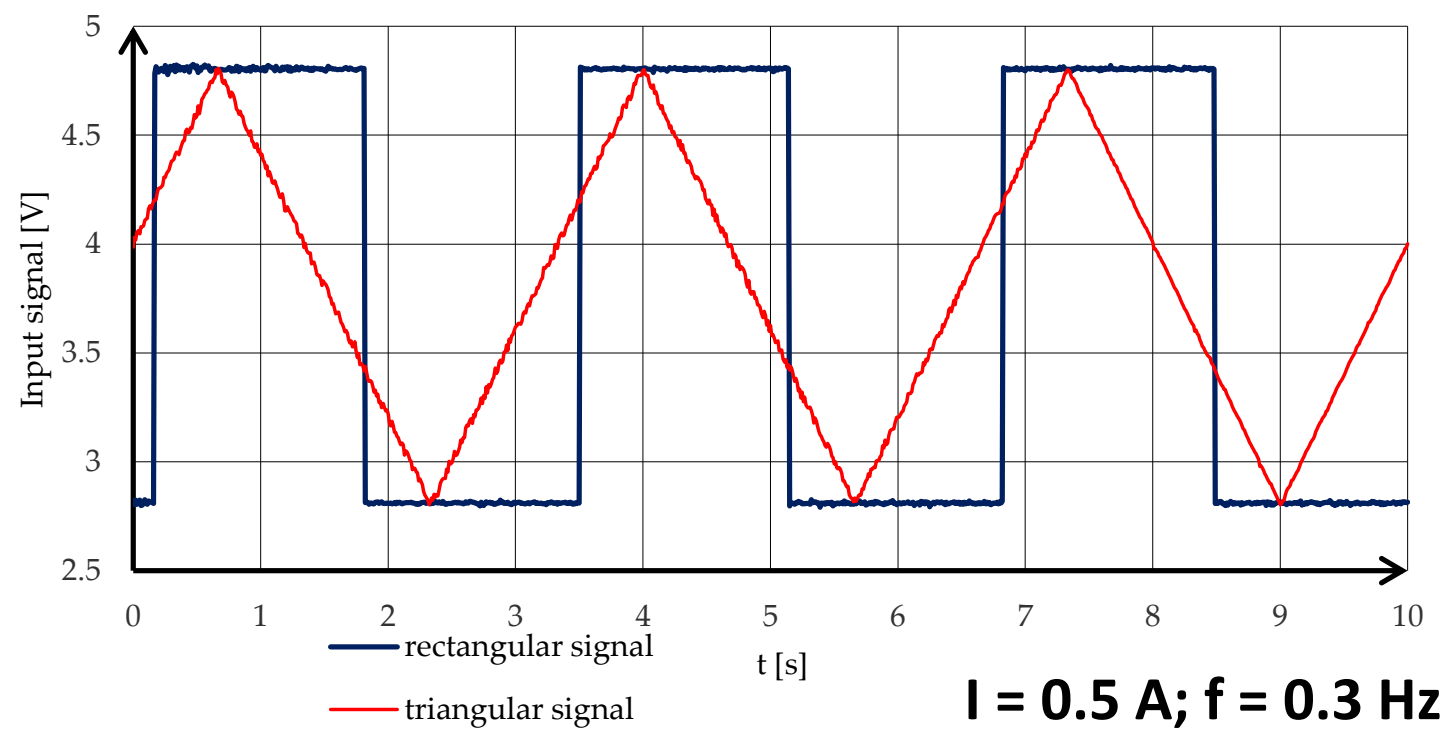

Figure 13. The variation in time of the signal type for a tested magnetorheological damper 
The damping characteristics of the damper for the two types of signals are shown in Figure and 14 and Figure 15. We find that the damping force developed by the magnetorheological shock absorber is higher compared to that developed by the classic shock absorber. We also notice that depending on the type of signal, the hysteresis loop also changes. Experimental research has determined the actual damping characteristics and revealed the influence of current intensity on these characteristics.

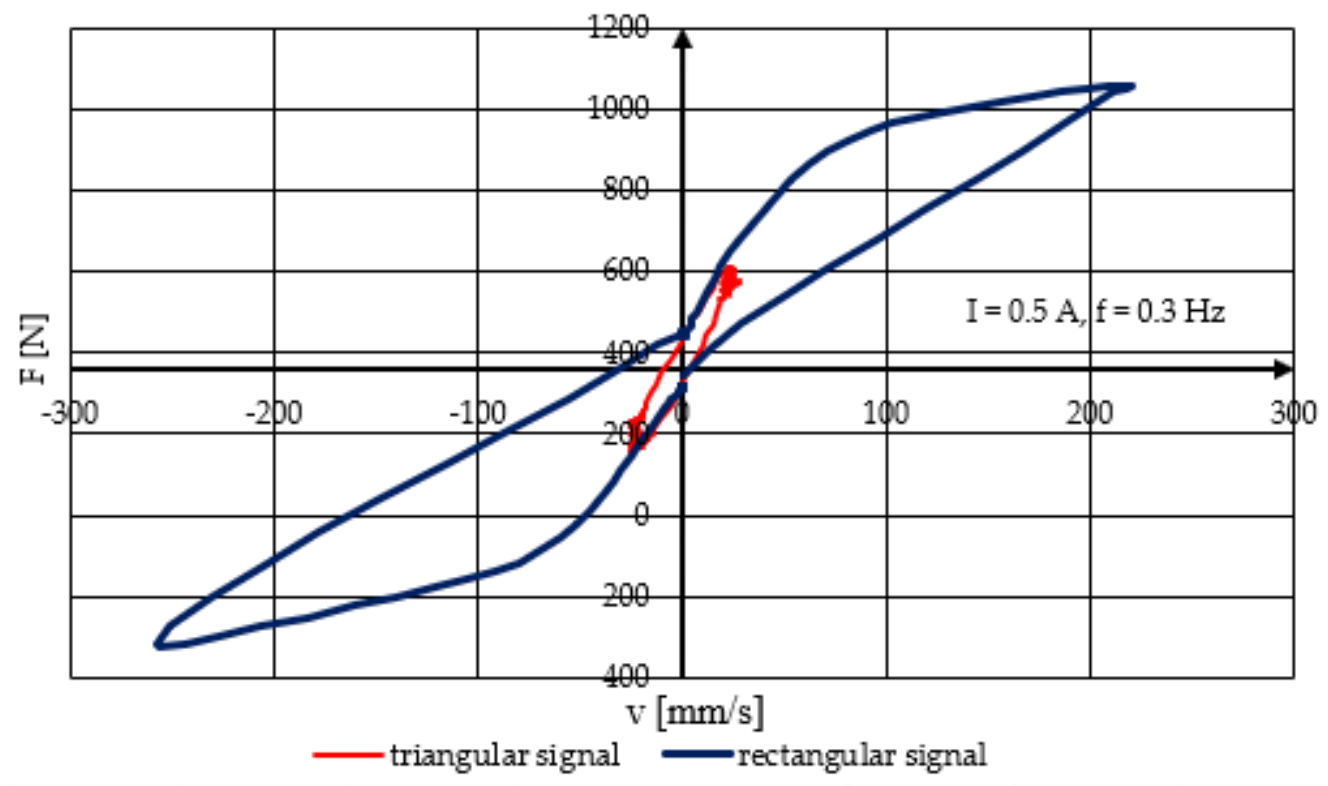

Figure 14. The damping characteristic of the magnetorheological shock absorber in force-velocity coordinates

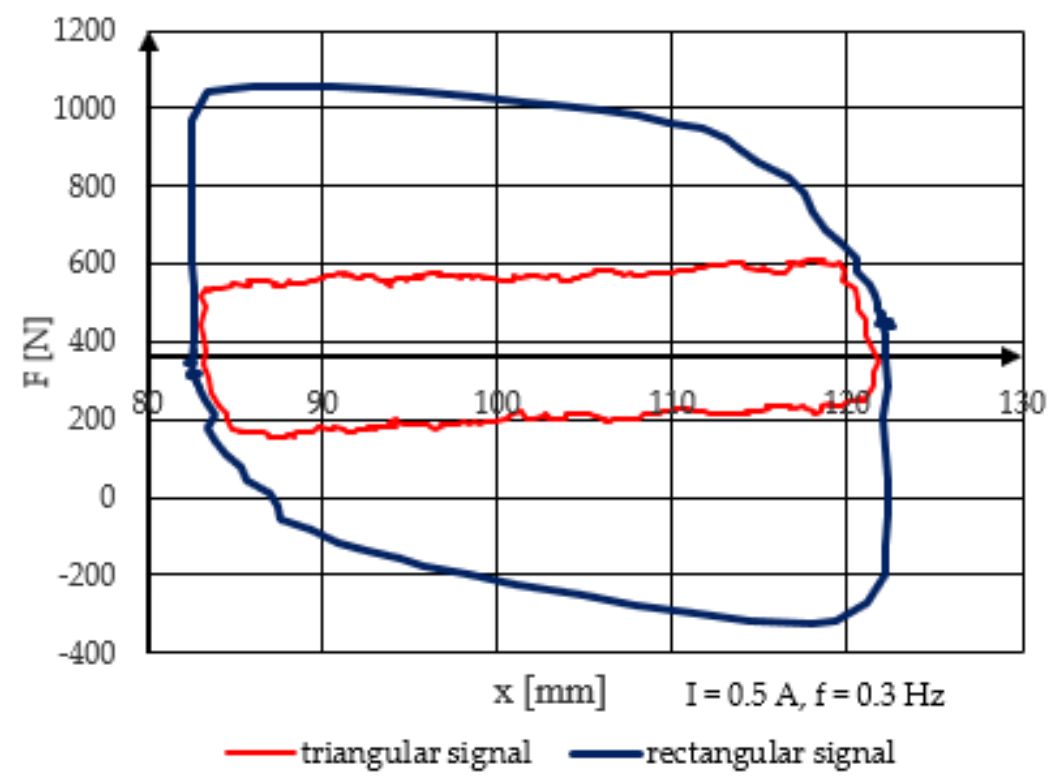

Figure 15. The damping characteristic of the magnetorheological shock absorber in force-displacement coordinates

Figure 16 shows the influence of the electric current intensity on the displacement of the magnetorheological shock absorber piston, for a sinusoidal signal with a frequency of $0.5 \mathrm{~Hz}$. The range in which the piston stroke varies is $80-120 \mathrm{~mm}$.

Figure 17 shows the variation of the maximum and minimum damping coefficient depending on the current intensity, for a magnetorheological damper, for a sinusoidal signal with a frequency of $0.5 \mathrm{~Hz}$. 
We notice how the magnetorheological shock absorber changes the value of its damping coefficient depending on the value of the electric current intensity. After a higher value of the electric current intensity, over 3 A the trend shows that the value of the damping coefficient of the magnetorheological shock absorber tends to saturate Figure 17.

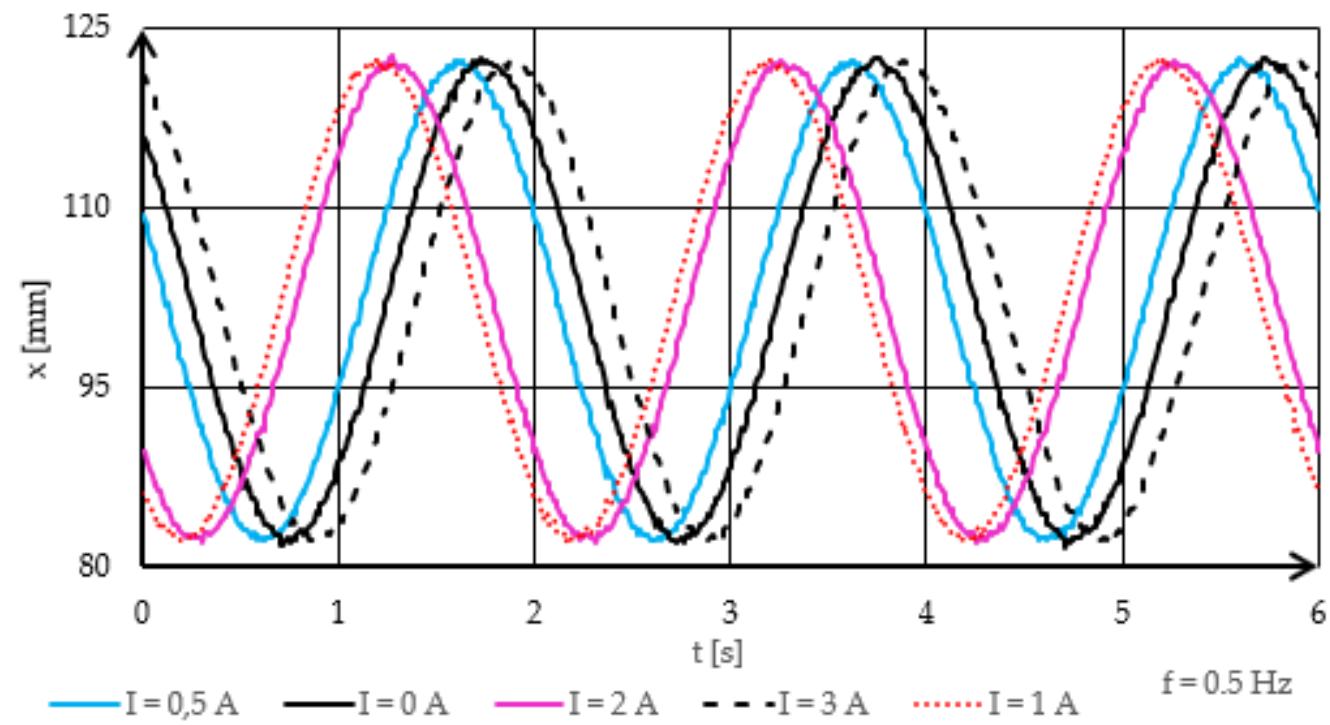

Figure 16. Time variation of the piston stroke of the magnetorheological damper, for different values of electric current intensity

The law of variation for the damping coefficient, respectively for the dissipated power by the magnetorheological shock absorber, as a result of the viscous friction approximates a polynomial.

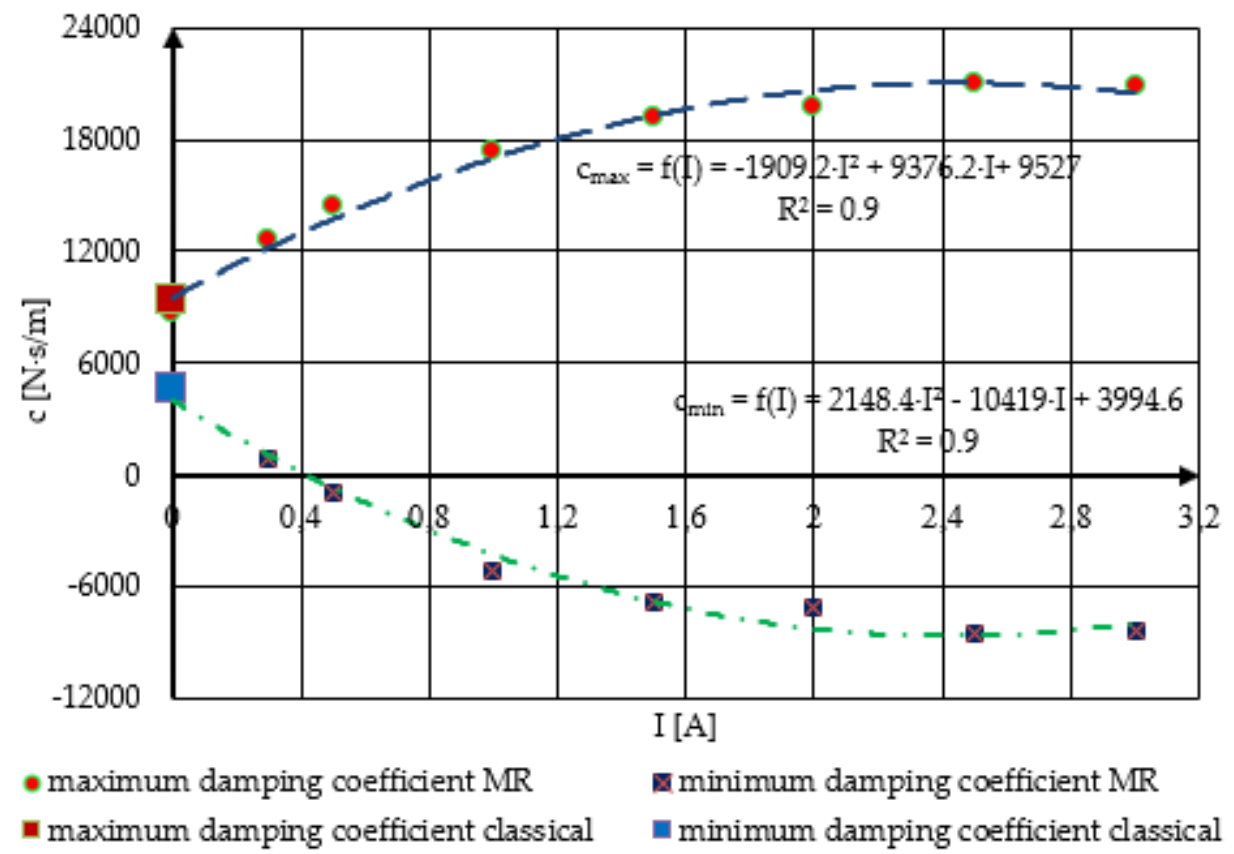

Figure 17. The maximum and minimum damping coefficient depending on the current intensity, for a magnetorheological damper

Figure 18 shows the dissipated power corresponding to the maximum forces, for different values of the electric current intensity for a magnetorheological damper, considering a piston speed of approximately $60 \mathrm{~mm} / \mathrm{s}$ and an input sinusoidal signal at a frequency of $0.5 \mathrm{~Hz}$. Over $3 \mathrm{~A}$ the tendency is for the dissipation power to saturate as well. 
The dissipated power curve, depending on the current intensity, shows a faster variation up to $1 \mathrm{~A}$, then it starts to have a slower variation. The power dissipated by the magnetorheological shock absorber is higher compared to that of the classic shock absorber.

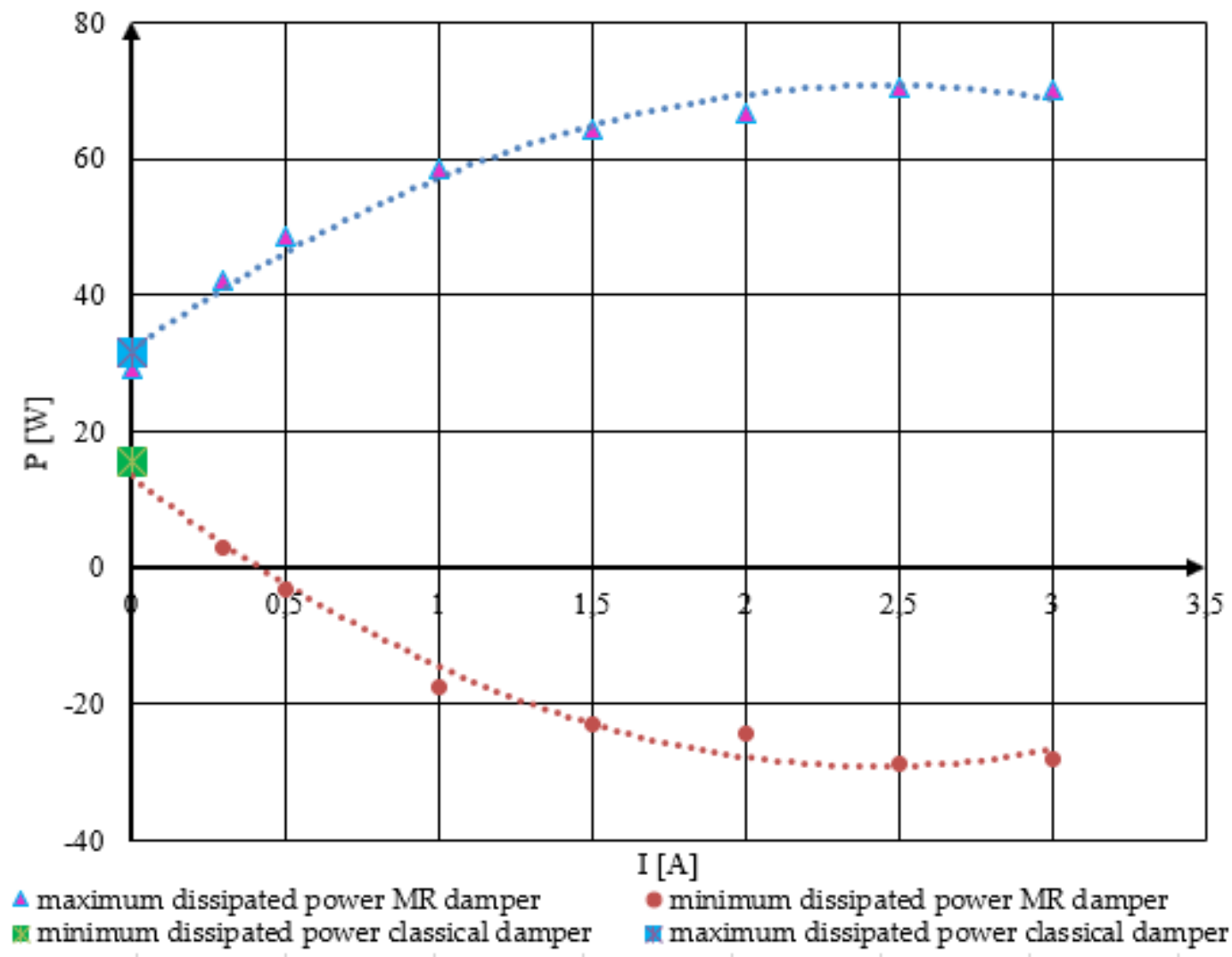

Figure 18. The maximum and minimum dissipate power depending on the current intensity, for a magnetorheological damper

The experimental research undertaken allowed to determine the real dynamic characteristics of the shock absorber and to identify the influence of the parameters on these characteristics.

\section{Discussion}

A high supply voltage of the damper (a few volts) is not required for the control of the magnetorheological fluids, the one offered by the battery being enough. The fundamental property of magnetorheological fluids is their ability to change their viscosity in the presence of a magnetic field. The most important aspect, on which depends the control of the behavior of a magnetorheological fluid, is the response time to the intensity of the magnetic field. It depends on the size and shape of the ferromagnetic particles, the viscosity of the fluid, the conductivity of the particle etc. To control the damping force to obtain the desired value there are three semi-active control methods: skyhook, groundhook and sky-groundhook. The skyhook controller is used in order to improve the quality of driving, by suppressing the movement of the body, and the groundhook to improve the stability of the steering, by suppressing the movement of the tire. A sky-groundhook controller is used to solve both problems.

Additives are used to improve the properties of magnetorheological fluids. They are used to delay the sedimentation of particles, as well as to prevent redispersion difficulties. An important factor to consider when developing the composition of a magnetorheological fluid is the rate at which sedimentation occurs.

From the point of view of fluid mechanics, the behavior of MR fluid in the absence of a magnetic field can be described by Newtonian mechanics, while in the presence of the magnetic field, it manifests the behavior of Bingham. 
MR fluids are not sensitive to impurities and contamination that may occur during manufacture and operation. Devices that use MR fluids require low power, below $50 \mathrm{~W}: 12-24 \mathrm{~V}$ and 1-2 A [11,17]. Conventional batteries can easily provide this power. This is also confirmed by the results of the experimental research.

Passive suspensions are digitally controlled, thus becoming essential comfort elements of luxury and sports cars. Due to the high cost, active suspensions are mainly used for military vehicles and high-end luxury class vehicles. Semi-active suspensions are beginning to become economically feasible, as they achieve a trade-off between price and performance, offering comfort close to that of an active suspension with an acceptable cost and reasonable fuel consumption. Among the semiactive suspension variants, the magnetorheological ones are also the most used, because they are cheaper, and the magnetorheological fluid can be controlled more easily, compared to the electrorheological one.

\section{Conclusions}

Modern classic mono-tubular shock absorbers have two-disc valves with different diameters, which are insensitive to temperature variation and thus to viscosity variation.

The results obtained from the experimental determinations show a significantly improved comfort when using a magnetorheological shock absorber, compared to a classic one, by the fact that the magnetorheological shock absorber allows to modify the damping coefficient according to the road conditions, thus maintaining the permanent contact between the tire and the road increase in damping force.

Following experimental research, it was found that the rectangular input signal demands more damping compared to the rest of the signals.

Modification of the stiffness of the suspension, associated with the modification of the damping (so that the relative damping remains unchanged) leads to low variations in the comfort of the car and the safety of ensuring the permanent contact of the wheels with the road. When moving the car, the dynamic forces taken over by the shock absorbers are quite high.

The variation of the damping force depending on the intensity of the electric current shows that it does not vary linearly, but parabolically, the force reaching $1250 \mathrm{~N}$, at a current of 3 A. Analysis deduced from the variation of the damping coefficient, the damping force changing its value depending on the value of the damping coefficient, which changes due to the viscosity of the fluid.

Author Contributions: Design, execution, commissioning and calibration of a complex stand for evaluating the performance of hydraulic shock absorbers magnetorheological and classical.

Acknowledgments: The author are grateful to Professor Nicolae Vasiliu, Member of the Romanian Technical Science Academy, head of Fluid Power Laboratory of University Polytechnic of Bucharest for the permanent technical assistance.

Conflicts of Interest: The author declares no conflict of interest.

\section{References}

1. Sharma, S. K.; Kumar, A. Ride Comfort of a Higher Speed Rail Vehicle Using a Magnetorheological Suspension System. Proceedings of the Institution of Mechanical Engineers, Part K: Journal of Multi-Body Dynamics 2018 232(1), 32-48. [doi.org/10.1177/1464419317706873]

2. Sireteanu, T.; Mitu., A.M.; Ghiță, G.; Niculescu, A.; Jankowski, A.; Kowalski, M. A Novel Device with Variable Friction for Shock and Vibration Control. Journal of KONES Powertrain and Transport 2017 24(3) 2017, 261-268. [DOI: 10.5604/01.3001.0010.3091]

3. Gurubasavaraju, T.M.; Kumar, H.; Arun, M. Optimisation of Monotube Magnetorheological Damper under Shear Mode. Journal of the Brazilian Society of Mechanical Sciences and Engineering 201739, 2225-2240 [https://doi.org/10.1007/s40430-017-0709-9]

4. Rahman, M.; Ong, Z.C.; Julai, S.; M.M., Ferdaus; Ahamed, R. A Review of Advances in Magnetorheological Dampers: Their Design Optimization and Applications. Journal of Zhejiang University-SCIENCE A 2017 18, 991-1010. [https://doi.org/10.1631/jzus.A1600721] 
5. Mitroi, M.F.; Chiru, A. Aspects Regarding the Identification of Optimum Driver Comfort Level by Virtual Analysis of the Vertical Oscillations Generated by Road. The 30th SIAR International Congress of Automotive and Transport Engineering SMAT, Craiova, Romania, 23 - 25 October 2019; Dumitru I., Covaciu D., Racila L., Rosca A. Eds.; Springer, Cham, Switzerland, 2019. [https://doi.org/10.1007/978-3-03032564-0_27]

6. Castravete, Ș.C; Marinescu, G.C., Dumitru, Dumitru, N., Oțăt, O.V. Finite Element Quarter Vehicle Suspension Model under Periodic Bump and Sinusoidal Road Excitation. Applied Mechanics and Materials 880, 163-170. Craciunoiu, N.; Dumitru N.; Roşca, A.S. Eds; Trans Tech Publications, Ltd., Switzerland, 2019. [doi: 10.4028/www.scientific.net/amm.880.163]

7. Al-Ashmori, M.; Wang, X. A Systematic Literature Review of Various Control Techniques for Active Seat Suspension Systems. Applied Sciences 202010 [doi: 10.3390/app10031148]

8. Ab Talib, M.H.; Mat Darus, I.Z.; Mohd Samin, P. Fuzzy Logic with a Novel Advanced Firefly Algorithm and Sensitivity Analysis for Semi-active Suspension System Using Magneto-rheological Damper. Journal of Ambient Intelligence and Humanized Computing 2019 10, 3263-3278. [https://doi.org/10.1007/s12652-018-10444]

9. Benxiang, J. The Simulation and Optimization of the Magnetic Circuit for Magnetorheological Damper. International Journal of Magnetics and Electromagnetism 2019 5(1). [doi: 10.35840/2631-5068/6516]

10. Weber, F.; Distl, H.; Fischer, S.; Braun, C. MR Damper Controlled Vibration Absorber for Enhanced Mitigation of Harmonic Vibrations. Actuators 2016, 5(4). [doi: https://doi.org/10.3390/act5040027]

11. Gołdasz, J.; Sapiński, B. Insight into Magnetorheological Shock Absorbers, Springer, Switzerland, 2015. [doi: 10.1007/978-3-319-13233-4]

12. Savaresi, S.M.; Poussot-Vassal C.; Spelta C.; Sename, O.; Dugard, L., Suspension Control Design for Vehicles, Elsevier Ltd., 2010, ISBN: 978-0-08-096678-6.

13. Hui, J.; Yeqing, H.; Songlin, N.; Fanglong, Y. Research on Semi-Active Vibration Control of Pipeline Based on Magneto-Rheological Damper. Applied Science 2020 10(7). [https://doi.org/10.3390/app10072541]

14. Saransh, J.; Shubham, S.; Pruncu, C.I. Performance Investigation of Integrated Model of Quarter Car SemiActive Seat Suspension with Human Model. Applied Science 2020 10(9). [https://doi.org/10.3390/app10093185]

15. McManus, S.J.; Clair, K.A.; Boileau, P.E.; Boutin, J.; Rakheja, S. Evaluation of Vibration and Shock Attenuation Performance of a Suspension Seat with a Semi-Active Magnetorheological Fluid Damper. Journal of Sound and Vibration 2002 253(1). [https://doi.org/10.1006/jsvi.2001.4262]

16. Kyung-In, J.; Byung-Kon, M.; Jongwon, S.; A behavior model of a Magnetorheological Fluid in Direct Shear mode. Journal of Magnetism and Magnetic Materials 2011 323(10). [https://doi.org/10.1016/j.jmmm.2010.11.039]

17. Choi, S.B.; Han, Y.M. Magnetorheological Fluid Technology-Applications in Vehicle Systems, Publishing House CRC Press, 2013, ISBN-13: 978-1-4398-5674-1.

18. Vasiliu, N.; Vasiliu, D.; Călinoiu, C.; Pulhaschi, R. Simulation of Fluid Power Sistem with Simcenter Amesim, CRC Press Taylor \& Francis Group, 2018, ISBN-13: 978-1-4822-5355-9. 